\title{
THE YELLOW-BELLIED MARMOT AND THE EVOLUTION OF POLYGAMY
}

\author{
Jerry F. Downhower ${ }^{1}$ and Kenneth B. Armitage
}

Section of Neurobiology and Behavior, Comell University, Ithaca, New York 14850; and Department of Biology, University of Kansas, Lawrence, Kansas 66044

This paper presents a model of polygamous mating systems based on studies of yellow-bellied marmot populations. In developing the model, we assume that the social systems of this species represent adaptations to existing ecological conditions and that they arose through natural selection. Evidence from other organisms that supports these assumptions was reviewed by Crook (1965), Lack (1968), Verner and Willson (1969), Brown (1964, 1969), Eisenberg (1966), and Fisler (1969), but these authors have differed in their interpretation of the role of natural selection.

Orians (1969) assumes that polygamy is always advantageous to males and hence its evolution rests primarily on its advantages or disadvantages to the female. Similarly, Verner and Willson (1966) suggest that polygamy arises only when it is advantageous to both sexes. We will present evidence that such assumptions are too restrictive and may not apply in all cases.

Wynne-Edwards (1962) argues that the primary function of social behavior is to provide information on population size, so that members of the population can adjust their procreation rate to the carrying capacity of the environment. As a consequence, those groups that best regulate their numbers will be selected for. Objections to such "group selection" based on analyses of social behavior are given by Lack (1966), Crook (1965), and McLaren (1967). Crook (1964), in his exhaustive study of weaver birds (Proceinae), demonstrated that many aspects of their behavior are closely linked with their mating system and its ecological determinants. He argues, in contrast to Wynne-Edwards, that these correlations are explainable as mechanisms which tend to increase individual fitness.

Discussions of mating systems, however, are often concerned only with the distribution of various mating systems among species or groups, and do not consider the origin of social conventions within a mating system. For example, Cohen (1969) describes the distribution of troop sizes in a number of primate species, but his model provides no insight into the dynamics of these groups. Our model will lead to an evaluation of behavior patterns within groups, as well as a description of the relative frequency of different mating systems.

1 Present address: Department of Zoology, Ohio State University, Columbus, Ohio 43210. 


\section{BACKGROUND}

The yellow-bellied marmot, Marmota flaviventris (Audubon and Bachman), occurs throughout the alpine areas of the Rocky Mountains (Hall and Kelson 1959). Since 1962 we have been studying populations of these animals in the vicinity of Gothic, Colorado, where marmots hibernate about 7 months of the year. Their active period is from the first week of May until mid-September (D. Kilgore, personal communication). Copulation occurs in the 2 weeks following hibernation (Armitage 1965; Nee 1969). Gestation requires about 30 days (Armitage 1962) and young are born in the first weeks of June. During the period of our study, we arrived at Gothic in the first week of June and remained there until late August. Our observations provide no data on the number of females that a male might have copulated with, or estimates of harem size during the breeding season. During the time we were in the study area, the number of females in each harem was stable. We assume that the harem size in June represents both the harem size in the breeding season and the number of females with which the male copulates. If there is recruitment of pregnant females subsequent to the breeding season and prior to our arrival, some of the conclusions we have drawn are open to question. We have no data on this point and recognize this limitation of our study.

The young remain within the home burrow of the female for an additional 20-30 days post partum. They are usually first seen in our study area in the first week of July. Our estimates of litter size and of the number of young are based on counts of young that appeared in the study area. We do not know the number of females impregnated.

We have no evidence to indicate that marmots in our study area breed in their second summer; but known-aged females bred as 2-year olds (third summer). Nee (1969) recorded breeding among subadults in the Sierras, but failed to distinguish between yearlings and 2-year olds.

\section{METHODS}

Since 1962, we have trapped marmots at five of seven localities in the Gothic area; the localities were described by Downhower (1968). The study area is at an elevation of about $2,900 \mathrm{~m}$, surrounded by mountains over $3,800 \mathrm{~m}$ high. The farthest pair of colonies are less than $4 \mathrm{~km}$ apart. Trapping at locality 3 began in 1963 and was stopped in 1965. Data from that locality are excluded from this report. Trapping at locality 7 began in 1964.

Upon first capture, each marmot was marked with a pair of individually numbered metal ear-tags. These tags served as permanent identification for each animal. In addition to the ear-tags, each individual was given a unique mark on its fur with Nyazol fur dye which permitted visual census of the marmots at each locality. Thus we were able to determine when new individuals appeared at a locality, to associate young with their mother, to determine the number of unmarked individuals still at a locality, and to 
determine if any individuals had emigrated. We estimate that we identify and mark annually over $95 \%$ of all marmots at each locality.

Solitary marmots are sometimes seen on the periphery of each trapping locality and at certain places in the study area. A special effort was made to trap such individuals, especially at those places that annually sheltered one or two marmots or an adult female and her young.

Marmots are classified into young, yearlings, and adults. Young marmots appear in the colonies in midsummer, and are the smallest individuals present, weighing about $1 \mathrm{lb}$ when they first emerge above ground (Armitage and Downhower, in preparation). Marmots in their second summer of life are yearlings. Most yearlings we trap have been previously eartagged, hence their age is known. They may also be distinguished by their small size compared to an adult. In June, a yearling weighs $3-4 \mathrm{lb}$, whereas an adult weighs 6-13 $\mathrm{lb}$. If an untagged adult is trapped, size is used as the distinguishing character. There appear to be no reliable methods for further aging marmots (Davis 1964). Nee (1969) devised a scheme for distinguishing three age categories similar to ours on the basis of skull measurements, but his categories do not seem based on marked individuals of known age.

In previous studies of the yellow-bellied marmot, trapping localities have been referred to as colonies (Armitage 1962, 1965; Pattie 1967; Downhower 1968; Shirer and Downhower 1969). However, not all "colonies" in our study area were similar in social organization and, for our purposes, it will be useful to distinguish the social status of individual marmots as follows.

Armitage (1962) first applied the term "colony" to social groups of marmots he observed at Yellowstone. That colony consisted of an adult male and a harem of 7-16 adult females, plus individuals of nonreproductive age-yearlings and young. In this study the term "resident" will be applied to individuals in such polygynous groups. The term "transient" will refer to individuals of any age or sex that move through the study area but do not stay there for more than a few days. Finally, we have trapped a number of individuals that we call "isolates." These animals reside alone; they may be males or females of any age group. Transients may associate briefly with isolates.

The social status of an individual is not permanent. A resident one summer may be trapped as an isolate or transient the next. Transients or isolates may become residents. However, in our experience, individuals retain their status during the time we are in the study area.

Weather data used in this study are taken from U.S. Weather Bureau (1962-1968) records.

\section{POPULATIONS}

Locality 1.-From 1962 to 1964 this locality was occupied by two resident males and their harems. From 1965 to 1968 only one male was present. From 1966 through 1968, this resident male was also the resident male 
at locality 2. As the harem females at those two localities did not contact one another, each harem will be treated separately. Harem size varied from two to four females per year. No young were produced in 1964 or 1968. In those years when young were produced, some were recaptured the following spring.

Locality 2.-The harem size was one to four females. Young were trapped there each year; however, in 1963 and 1965, no yearlings were trapped.

Locality 4.-Usually only a pair of marmots was trapped here. In 1966 and 1967 two adult females were trapped. No young were trapped here in 1964 and 1965, and none of the litter produced in 1966 was recaptured in 1967.

Locality 5.-Three harems were present at this place. One (5b) was founded in 1964. Locality 5a supported two to seven adult females and produced no young in 1963. Locality 5b supported a pair of adults. Young were captured here each year. Young of a litter produced in 1965 were not retrapped in 1966. Locality 5c supported a harem size of one to four females. No young were trapped there in 1967.

Locality 6.-This place was occupied by an isolated female, her young, an occasional yearling, and transient males. In 1964, three transient males were trapped.

Locality 7.-The harem size was one to three females. Neither young nor yearlings were trapped here in 1968.

Transients and isolates were trapped in each year of the study. No young were born to isolated females in 1967.

\section{SEX RATIOS}

Previous studies of yellow-bellied marmot populations suggest that adult sex ratio favors females; this deviation was attributed to increased mortality among males (Armitage 1962; Pattie 1967). Nee (1969) saw one adult male and 10 adult females in his study area, but he trapped equal numbers of each sex. He suggested that males were more wary than females and hence not seen as often.

Our data reveal no significant deviation from a sex ratio of $1: 1$ (table 1). As mentioned above, polygynous groups are present in the study area, and at those places the adult sex ratio is unbalanced in favor of females. The sex ratio is restored to unity by the presence of transient and isolated adult males.

\section{COMPARISONS OF RESIDENTS AND ISOLATES}

Isolated females were sufficiently common in the Gothic area to evaluate their reproductive success. The mean litter sizes for isolated females and resident females are similar (table 2 ). The range of litter sizes for isolates was two to six young; the range of litter sizes for resident females was two to eight young. Isolated females produced litters less often than resi- 
TABLE 1

Sex Ratios among Yellow-belined Marmots Trapped in the Gothic Study Area

\begin{tabular}{cccc}
\hline \hline & & AGE & \\
\cline { 2 - 5 } Sex & Young & Yearling & Adult \\
\hline Male $\ldots \ldots \ldots \ldots \ldots \ldots \ldots \ldots$ & 135 & 70 & 51 \\
Female $\ldots \ldots \ldots \ldots \ldots \ldots$ & 157 & 88 & 66 \\
\hline
\end{tabular}

dent females; consequently, they produced fewer young per female. The range of litter sizes reported here is greater than that reported by Nee (1969) and Hayward (1952).

On the average, a resident female produces almost twice as many litters as an isolate, and she leaves approximately two young for every one left by an isolated female. The decreased reproductive success of an isolated female may be due to a reduced probability of insemination, or her inability, once impregnated, to bring her litter to weaning.

Few of the young born to isolated females are recaptured as yearlings. Of 29 young born to isolated females, only two have been recaptured as yearlings; whereas, of 263 young born to resident females, 132 have been recaptured as yearlings. The small number of recaptures of young of isolated females may be due to at least three causes: (1) isolates may occupy burrows less favorable for hibernation, hence overwintering mortality is greater; (2) young marmots born to isolated females disperse earlier than young of resident females; or (3) isolates fall victim to predators more frequently than residents. This last phenomenon would have to occur during dispersal, because we have not recorded any losses of isolates or residents during this study, although predators occur in the study area and there is evidence that marmots fall prey to them (Armitage 1962; Downhower 1968).

We conclude that isolated females are reproductively less successful than resident females, and that natural selection would favor females that associate with a resident male, that is, females in harems.

\section{FITNESS AND POLYGAMY}

To determine if there are differences in fitness between females in different sized harems it is necessary to consider both the number of young produced per female and the probability that those young survive. Together,

TABLE 2

Fertility of Isolated and Resident Female Yellow-bellied Marmots

\begin{tabular}{|c|c|c|c|c|}
\hline & $\begin{array}{l}\text { Number } \\
\text { of Litters }\end{array}$ & $\begin{array}{c}\text { Number } \\
\text { of Young } \\
\text { per Litter } \\
(\bar{Y} \pm \mathrm{SE})\end{array}$ & $\begin{array}{c}\text { Number } \\
\text { of Litters/ } \\
\text { Female } \\
\text { per Year } \\
(\bar{Y} \pm \mathrm{SE})\end{array}$ & $\begin{array}{l}\text { Number } \\
\text { of Young/ } \\
\text { Female } \\
\text { per Year } \\
(\bar{Y} \pm \mathrm{SE})\end{array}$ \\
\hline Isolates & $\begin{array}{ll} \\
\cdots\end{array}$ & $4.14( \pm .857)$ & $0.28( \pm .126)$ & $1.18( \pm .687)$ \\
\hline Residents & $\ldots \ldots \ldots 52$ & $4.50( \pm .187)$ & $0.50( \pm .081)$ & $2.29( \pm .403)$ \\
\hline
\end{tabular}


these two parameters estimate fitness as the number of individuals that a female contributes to the next generation.

For harems in the Gothic area, the number of young per litter is independent of harem size $(b=-0.18, t=0.276, P>.05)$. Females in large harems, however, reproduced significantly less often than females in small harems (fig. 1). Consequently, females in small harems produced more young on the average than females in large harems (fig. 2). The proportion of young surviving as yearlings does not increase with harem size $(b=0.02$, $t=1.05, P>.05)$. On the average, $48 \%$ of the young born to harem females were recaptured as yearlings.

For the most part, resident yearlings disperse from the harems, and mortality subsequent to their dispersal is independent of harem size. Hence, the regression of the number of yearlings per female on harem size is a measure of female fitness (fig. 3). This fitness is greatest when she is monogamous and decreases with increasing harem size (fig. 3). Ambedkar (1961, cited in Crook [1964]) reports a similar decreased fledging success in Ploceus phillipinus with increased harem size. As a consequence, females in polygamous matings are less fit than if they were monogamous. If mating systems are based solely on the advantages to the female (Orians 1969), we would expect marmots to be monogamous. As this is not the case, there must be some other explanation of polygamy in this species. Let us examine the consequences of the observed correlation.

A monogamous female is most fit and hence any female traits that promote monogamy will be selected for. It would seem advantageous for females to solicit the male and to respond aggressively toward other females. Such behavior should be linked with the reproductive cycle of the female. It would result in exclusion of other females from the harem and would

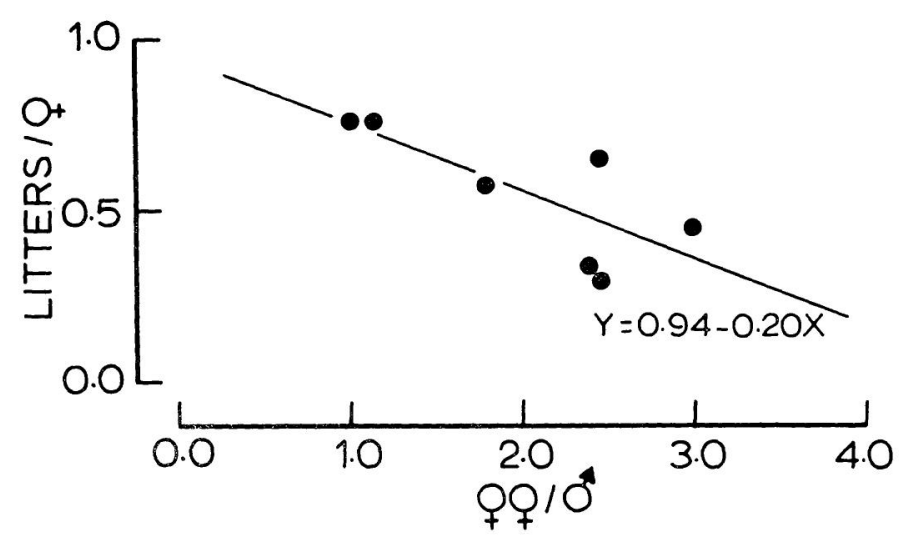

Fig. 1.-Changes in the number of litters per female as harem size increases. The data are the number of litters per female and the average harem size for each of seven harems in the study area. Five of the averages cover 7-year periods, two cover 5-year periods. The fitted linear regression is significant at $.05>P>.01(t=2.93)$. 


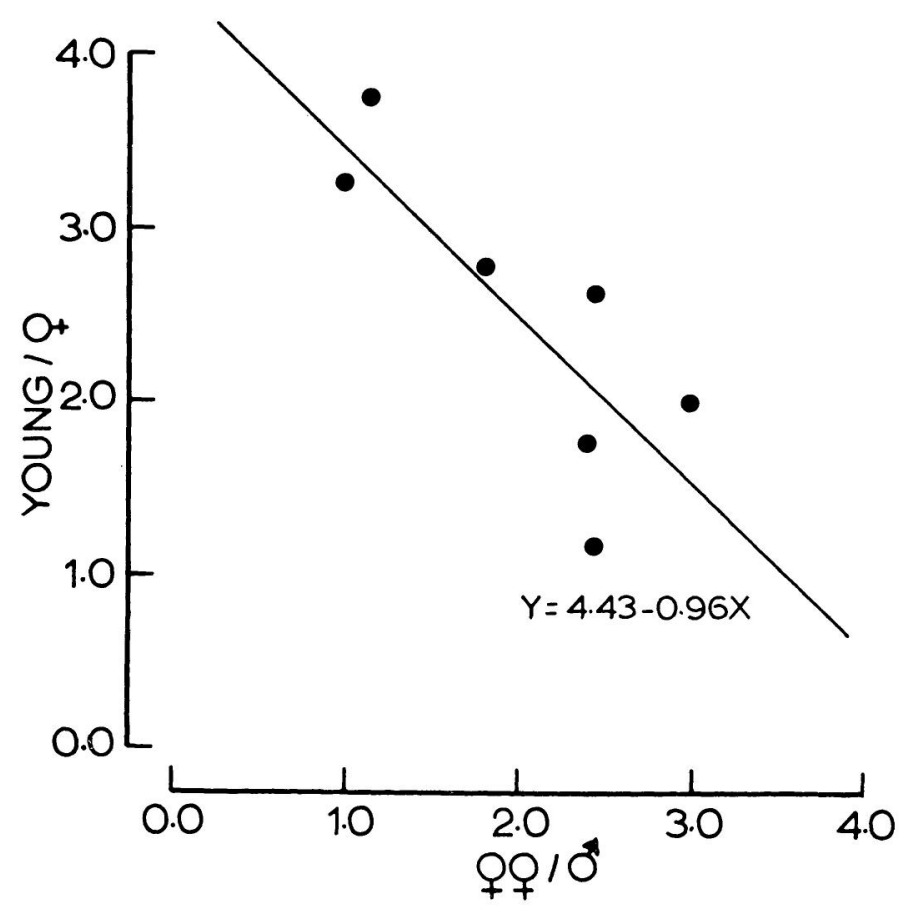

FIG. 2.-Changes in the number of young per female as harem size increases. The data are the number of young per female and the average harem size for each of the seven harems in the study area for the time periods stated in fig. 1 . The regression is significant at $.05>P>.01(t=3.06)$.

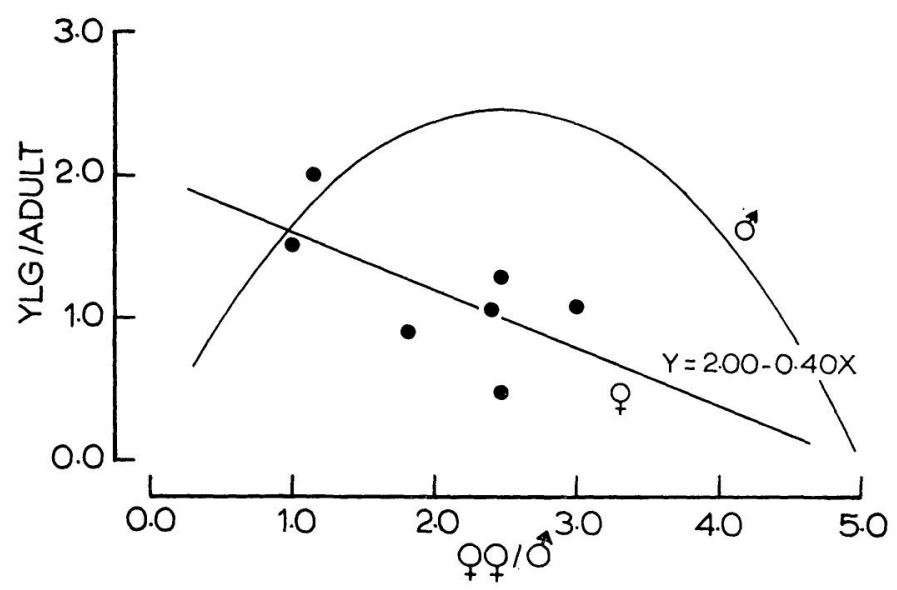

FIG. 3.-Changes in the number of yearlings per adult for harem females and the resident male as harem size inereases. The data are the number of yearlings per female and the average number of females per harem for each of the seven harems in the study area for the time periods stated in fig. 1. The linear regression is significant at $.05>P>.01(t=2.64)$. For further explanation of the "fitness" curve labeled with the male symbol see text. 
accentuate exclusion when it would be most important for a female, that is, when she has a litter. Hence, pregnant females should be more aggressive than nonpregnant ones.

Armitage (1965) provides field observations which support the foregoing analysis. In the first week after females emerged from hibernation, they all remained near the male's burrow. During the next several weeks, agonistic encounters among females increased with the result that females began to move away from the male's burrow. The male copulated with all females in the harem.

Our observations on interment behavior in this species (an aggressive interaction involving two marmots ending with one taking refuge in a burrow, and the other then filling in the burrow entrance) record only one instance when a resident male was involved (with another male) and seven instances involving adult females (Armitage and Downhower 1970).

Similarly, female red-winged blackbirds (Agelaius phoeniceus) and yellow-headed blackbirds (Xanthocephalus xanthocephalus) defend territories against other females but do not help the male defend his territory (Nero 1963; Nero and Emlen 1951; Orians 1961). Female tricolored blackbirds (A. tricolor) only occasionally react to other females, although this species is also polygamous (Orians and Christman 1968; Lack and Emlen 1939).

These observations are consistent with conclusions concerning the evolutionary strategy of harem females based on analyses of female reproductive success. Further, Michael (1969) finds that pregnant female rhesus monkeys (Macaca mulatta) become more aggressive during pregnancy. His experimental data on ovariectomized females indicate that aggressive behavior, at least in this species, is mediated by both estrogen and progesterone. Whether a similar relationship occurs in marmots remains to be demonstrated.

The fitness of a resident male is equal to the sum of the fitnesses of the females in his harem. Hence the fitness of a monogamous male is the same as his mate, whereas the fitness of a polygamous male is $N$ times the average fitness of the $N$ females in his harem. If the fitness of a resident male in the Gothic area is plotted for different harem sizes in the manner stated above, we see that males with two to three females are most fit (fig. 3). A male with a harem of four females is actually less fit than a monogamous male. We have few observations on large harems to support this aspect of the model, but the paucity of large harems is consistent with the model (see "Polygamy as a Reproductive Strategy,"' below).

Because a harem of two or three females represents the optimal mating association for a resident male, any traits that would allow a male to attract and maintain a harem would be selected for. Hence, males should react aggressively toward other males. The male should readily accept or attract females and should act to reduce aggressive interactions among females and coerce them to remain in the harem.

In an evolutionary sense, males and females share some goals, and differ 
on others. We suggest that the social structure within harems of marmots represents a behavioral resolution of those opposing tendencies. The resident male and his harem occupy only a small area of the colony during the reproductive season. Subsequently, females move away and seem to space themselves within the home range of the male. (In this respect, each female approximates a monogamous relationship with the male.) Dominantsubordinate relations among females seem to be based on their reproductive state (Armitage, in preparation). Insemination soon after emergence from hibernation is advantageous to harem females, since gestation and weaning take almost $40 \%$ of the total time during which the marmots are active. Areas occupied by isolates do not appear to be suitable for rearing young through their first winter, and thus it is more advantageous for a female to remain in a harem, if possible, than to leave. Increased aggressive interactions among harem females in the postreproductive period would also make it difficult for a female to enter a harem at that time (Armitage 1965).

\section{ENVIRONMENTAL FACTORS AND THE MATING SYSTEM}

In certain years, snow has been still on the ground when we arrive at the study area in June. In other years, the area may be free of snow in early May. Thus in some years, the growing season begins soon after the marmots emerge from hibernation, while in others it may be delayed until gestation is almost complete. As these animals hibernate for 7 months, we question if a female could successfully bring her litter to term in those years when the start of the growing season is delayed.

We postulate that a major determinant of the number of young produced by each female each year is the availability of food during gestation, and that the observed spatial distribution of females in the male's home range in the postreproductive period results from competition for food at a time when it may be limited. A female able to exclude other females from a limited food supply will increase the probability that she will bring her litter to term. Food does not appear to be limiting in midsummer when young are first seen in the study area. Hence we shall concentrate on the temporal availability of food in the environment.

We have used two measures to estimate the start of the growing season: (1) the last day with accumulated snow, and (2) the last snow fall or the last day with accumulated snow (whichever occurred latest). The weather data are for Crested Butte, Colorado (table 3). Crested Butte is 7 miles by road from the study area and about $300 \mathrm{~m}$ lower in elevation. The growing season starts about 1 month later at Gothic.

There is a positive correlation of the number of young per female with the last snowfall of the year (table 4). That is, the later the start of the growing season, the fewer young that were produced.

Harem size appears to be related to the start of the growing season. Harems were larger in those years when the start of the growing season was 
TABLE 3

Estimates of the Start of the Growing Season IN Various Years FOR Crested Butte, Colorado

\begin{tabular}{|c|c|c|c|}
\hline & Year & $\begin{array}{l}\text { Last Day with } \\
\text { Accumulated Snow }\end{array}$ & $\begin{array}{c}\text { Last Snowfall or } \\
\text { Last Day with } \\
\text { Accumulated Snow } \\
\text { (Whichever Occurred } \\
\text { Later) }\end{array}$ \\
\hline 1962 & $\cdots$ & . April 25 & April 25 \\
\hline 1963 & $\ldots \ldots \ldots$ & ... March 30 & April 28 \\
\hline 1964 & $\ldots \ldots \ldots$ & ... May 2 & May 8 \\
\hline 1965 & $\ldots \ldots \ldots$ & ... May 3 & May 25 \\
\hline 1966 & $\ldots \ldots \ldots \ldots$ & ... March 25 & April 20 \\
\hline 1967 & $\ldots \ldots \ldots \ldots$ & ... April 5 & May 6 \\
\hline 1968 & $\ldots \ldots \ldots \ldots$ & ... May 4 & May 15 \\
\hline
\end{tabular}

delayed. This relationship is consistent with the previous analysis of the optimal harem sizes for males and females and the different behavior associated with each sex. In those years when the start of the growing season is delayed, fewer pregnancies are successfully completed. As a consequence, aggressive behavior of females is lowered and the main factor determining harem size is the ability of the male to recruit females and minimize aggressive interactions between them. Hence, in those years when the start of the growing season is delayed, the mean harem size increases. Conversely, in those years when the growing season is early, a larger proportion of females bring litters to term, and aggressive interactions between pregnant females would be expected to determine harem size.

\section{POLYGAMY AS A REPRODUCTIVE STRATEGY}

If the start of the growing season is a random variable, and harem size is determined by the interaction of the different reproductive strategies of the male and his harem, then the distribution of harem sizes over years and localities may be estimated as a function of the relative mean fitnesses of different sized harems. The mean fitness of a harem of $N$ females is

$$
\bar{X}_{w N}=\frac{N\left(w_{f}\right)+w_{m}}{(N+1)}
$$

where $w_{f}$ is the fitness of a harem female in a harem of $N$ females and $w_{m}$ is the fitness of a male with a harem of $N$ females. The mean fitnesses for harems of one to four females were calculated from the fitted curves in

TABLE 4

Spearman's Rani Correlations of the Start of the Growing Season with Harem Size and Fertility of Harem Females $(N=7)$

\begin{tabular}{lllc}
\hline & & $\begin{array}{c}\text { Mean No. of } \\
\text { Females/Harem }\end{array}$ & $\begin{array}{c}\text { Mean No. of } \\
\text { Young/Female }\end{array}$ \\
\hline Last day with accumulated snow $\ldots \ldots \ldots \ldots \ldots$ & -0.54 & 0.61 \\
Last snowfall $\ldots \ldots \ldots \ldots \ldots \ldots \ldots \ldots \ldots \ldots \ldots \ldots$ & $-0.82^{*}$ & $0.82^{*}$ \\
\hline
\end{tabular}

* Significant at $P<.05$. 
figure 3. The fitness estimates were summed over the range of harem sizes, and the relative fitnesses of different sized harems were reexpressed as the relative proportion of the total fitness attributable to each harem size. These relative proportions were then converted to an expected frequency of harems of different sizes, and the expected frequency was then compared with the observed frequency of harems of different sizes. There is a close correspondence between the observed and expected frequencies (table 5). The two distributions are similar.

The foregoing analysis ultimately rests on the fitness of a female in harems of different size. The optimal harem size for a male depends on the rate of change of female fitness with harem size. If the average fitness of a female is too depressed by the addition of a second female to the harem, then it may be more advantageous for the male to be monogamous. For example, in certain species of birds where the male helps to raise the young, a bigamous male may be unable to aid two females simultaneously, and consequently he may fledge fewer young than a monogamous male.

The degree to which the average fitness of a female can be depressed, while retaining the fitness of bigamous matings above that of monogamous ones, can be estimated in the following way. Let $a$ be the fitness of a female when she is monogamous and $b$ be the change in fitness of a female as females are added to the harem ( $b$ may be positive or negative). The fitness of a female at any harem size is

$$
w_{f}=a+(N-1) b .
$$

Similarly, the fitness of the male is

$$
w_{m}=N[a+(N-1) b] .
$$

The mean fitness of a harem with $N$ females is calculated as in equation (1). By substitution equation (1) becomes

$$
X_{w N}=\frac{2 N[a+(N-1) b]}{(N+1)} .
$$

TABLE 5

Comparison of Observed and Expected Frequencies of Harems of Different Sizes

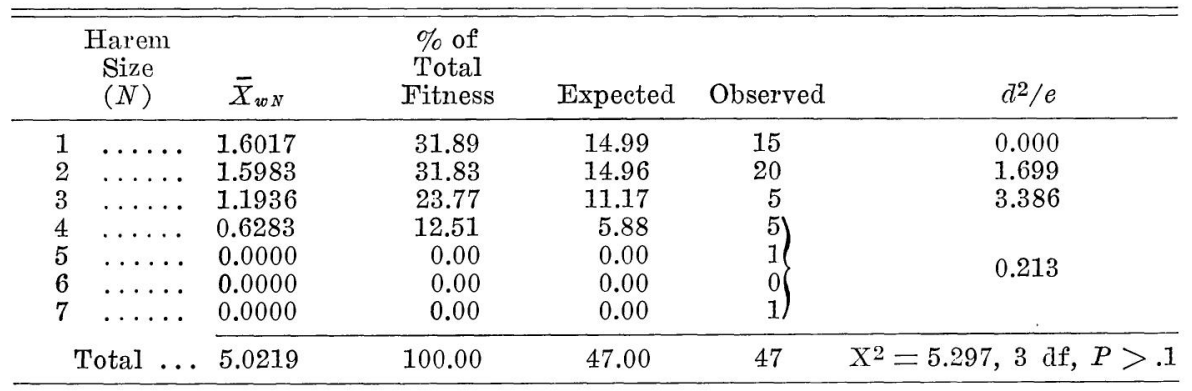

NotE.-Expected frequencies are based on calculated mean fitnesses $\left(\bar{X}_{w N}\right)$ of different sized harems. The calculated values of $a$ and $b$ are 1.6017 and 0.4030 , respectively (see text for meaning of these parameters). 
If $a$ is held constant, then $b$ in expression (4) can be evaluated for those situations where the mean fitness of a harem of $N$ females is equal to the mean fitness of a harem of $N+1$ females. These values represent the upper and lower thresholds for harems of different sizes.

If $b$ is small, then the optimal harem size is large (fig. 4). When $b$ is small, a slight change in its value results in another harem size being optimal. A large value of $b$ results in a small harem being advantageous. Here though, a small change in $b$ will not affect the optimal harem size, unless $b$ is in the vicinity of a threshold. In a relative sense, monogamous matings are more resistant to change than polygamous ones. That is, an environmental change must be of large magnitude and long duration for bigamy to be favored over monogamy. As such changes may be rare at a single place, it is not surprising that monogamy is often accompanied by behavioral conventions conducive to pair formation and maintenance, as, for example, pair bonds among passerines. However, if a species occurs over an appropriate environmental gradient, the mating systems should vary in a predictable manner. Orians (1961) and Verner (1964) discussed polygamy in certain marsh birds-redwing and yellow-headed blackbirds, and longbilled marsh wrens, respectively-and found that polygamous males occupied sites which have an abundance of food, whereas monogamous males occupy sites of poorer quality.

In species that maintain large harems, small environmental changes may

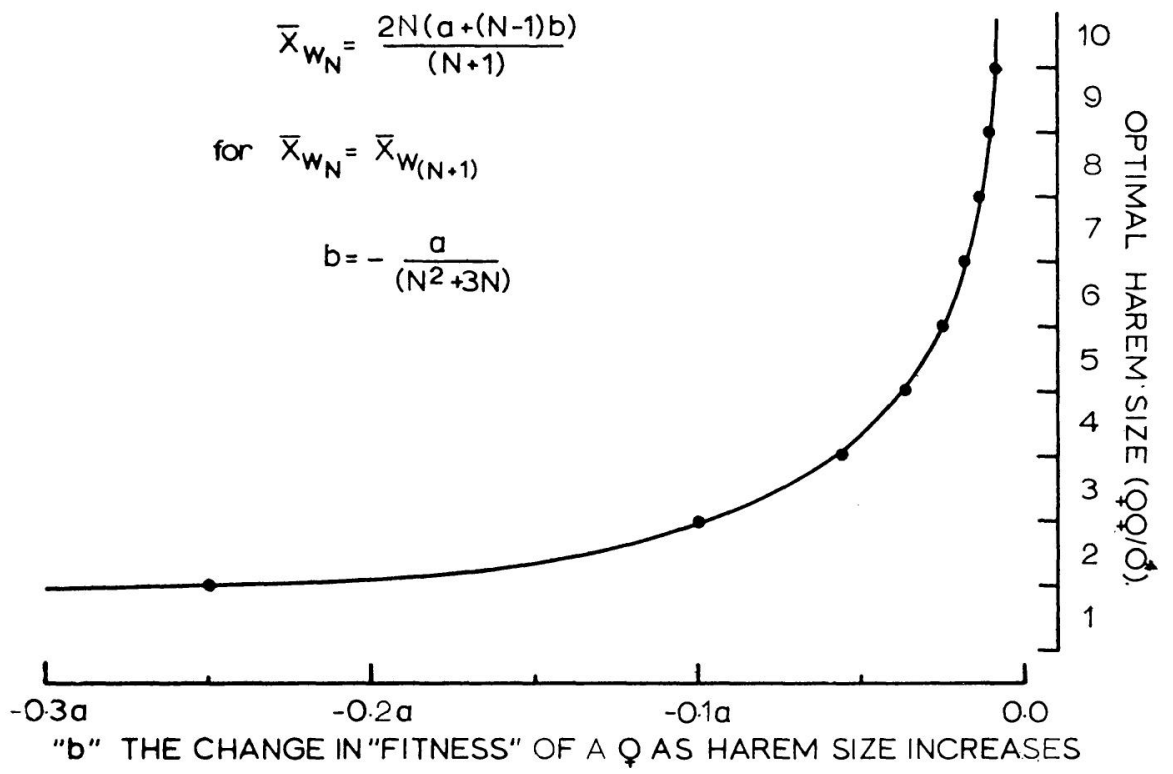

FIG. 4.-Expected optimal harem size as estimated by the mean fitness of individuals in different sized harems $\left(\bar{X}_{w N}\right)$, for various changes in the average fitness of a female with increased harem size (b). All symbols are defined in text. 
have a different effect. Because large harem size is optimal when $b$ is small, and specific harem sizes are optimal for only a small range of $b$ values, large harems might be expected to respond to small, short-term changes. Males in certain pinniped species maintain large harems, and, while extensive data on harem variation are not available, Rand (1955) reports that females of the cape fur seal (Arctocephalus pusillus) will leave one harem and join another. Bartholomew and Hoel (1953) report that large harems of the Alaskan fur seal (Callorhinus ursinus) are more variable than small harems.

When $b$ is small, the addition of a female to the harem does not greatly affect the fitness of the other females. Hence larger harem size should be accompanied by reduction of aggressive responses among females. Females in large harems should be tolerant of each other. Among polygynous pinnipeds, females are gregarious and aggressive interactions are limited to males (Bartholomew 1952; Bartholomew and Hoel 1953; Hewer 1960; Bertram 1940).

Mating systems appear to be adaptations to environmental circumstances, and selection will lead to adaptations to the mean environmental circumstance. Hence, the foregoing analysis has treated the situation where the change in $b$ is not transitory. When $b$ is small, however, small shifts on an annual or shorter-term basis will make it difficult for a specific size harem to be selected for at a given place. Hence large harems may respond positively to factors that would reduce $b$. Short-term fluctuations will have a different effect when the optimal harem size is small. Here transient conditions that superficially resemble changes in $b$ will result in changes in the competitive ability of males and females to maximize their optimal fitness. Consequently, these changes will be opposite from those predicted if the change were a long-term one.

We have postulated, for marmots, that food limitation during gestation is the factor determining reproductive success of females. That is, the availability of food in early spring determines $b$. It is to be expected that harems of marmots at places where food is abundant in that period should be larger than at Gothic. The harem at Yellowstone (Armitage 1962) was bisected by a hot spring. Vegetation was available along the banks of the spring early each spring; and variation in the start of the growing season was damped. The harem size at that locality was 7-16 females, three to eight times the average harem size recorded for the Gothic area. By contrast, when the growing season began early at Gothic, harems were small. Regrettably, these observations do not allow the effect of the amount of the resource to be distinguished from the predictability of the environment.

An infectious disease may also be considered a transient effect that would appear to increase $b$ and hence "select" for a smaller harem size. Medically, quarantine is used to reduce the spread of such disease. However, we would expect an epidemic to reduce the number of young produced and consequently a male would be more effective in recruiting and holding females. Hence, disease should be accompanied by an increase in harem size. Data on postepidemic howler monkey troops (Carpenter 1962) are consistent with 
this expectation. Fewer immature animals were present and the ratio of females to males was higher than that recorded for nonepidemic populations.

The foregoing model can lead to descriptive statements of the distribution of polygamous mating systems in birds and mammals similar to those expressed by Orians (1969). However, it also provides a basis for interpretation of behavioral traits within different mating systems, and for the experimental study of such systems.

\section{SUMMARY}

We have elaborated a model describing the development of polygynous mating systems. The bases of the model are measures of fertility and survival of adult females and their offspring, respectively, as functions of increasing harem size. Our data indicate that an adult female makes her greatest contribution to the next generation (is most fit) when she is monogamous. A second curve describing the fitness of the harem master with increasing harem size indicates that he is maximally fit when he maintains a harem of two or three females.

Consideration of the optimal mating system for each sex leads to predictions concerning the types of behavior that would allow each sex to realize its optimal mating system. Females should react aggressively toward other females and solicit the attentions of the male. The aggressive behavior of the female should be linked with her reproductive state. Pregnant females will be more aggressive than nonpregnant females. The male, on the other hand, should actively recruit females and act to pacify interactions between females. These expectations are realized in marmots and a number of avian species.

The reproductive success of females in the Gothic area is affected by the availability of food during gestation. When the growing season is early, more young are produced. In those years, however, the mean harem size is smaller, apparently due to increased aggression among adult females.

The different reproductive strategies of males and females, and the influence of food availability on those strategies, lead to the prediction that bigamous matings should be the commonest mating type. This prediction is verified by our field data. It should be noted that bigamy is disadvantageous, relatively, to both males and females.

A general formulation of optimal harem size based on the fitness of a male and the females in his harem is given. Large harems are expected to be variable and aggression among females should be reduced. Observations on pinnipeds support these predictions. Small harems would appear to be more stable. Consequently, behavior that would lead to pair formation and maintenance are expected. Pair-bonding in monogamous species of birds is in keeping with this prediction. When the optimal harem size is small, transient perturbations have effects opposite to those expected on a long-term basis. The effect of food abundance on marmots at Gothic is a decrease in mean harem size. 


\section{ACKNOWLEDGMENTS}

G. A. Bartholomew, J. H. Brown, J. Cohen, J. Eisenberg, J. M. Emlen, M. Konishi, G. Orians, and W. Schaffer all read various drafts of the manuscript. We thank them for their comments and criticisms. J. W. Bradbury and S. T. Emlen provided stimulating discussion, criticisms, and encouragement throughout the preparation of the paper. Special thanks go to the reviewers of this paper and to the editor of the journal for thoughtful and constructive commentaries that greatly helped pull the fabric of the paper together. R. R. Fleet and D. M. Michener helped with the fieldwork. This project was supported by NSF grants G16354 and GB1980 to K. B. Armitage.

\section{LITERATURE CITED}

Armitage, K. B. 1962. Social behaviour of a colony of the yellow-bellied marmot (Marmota flaviventris). Anim. Behav. 10:319-331.

1965. Vernal behaviour of the yellow-bellied marmot (Marmota flaviventris). Anim. Behav. 13:59-68.

Armitage, K. B., and J. F. Downhower. 1970. Interment behavior in the yellow-bellied marmot. J. Mammal. 51(1):177-178.

Bartholomew, G. A. 1952. Reproduction and social behaviour of the northern elephant seal. Univ. California Pub. Zool. 47 (15):369-472.

Bartholomew, G. A., and P. G. Hoel. 1953. Reproductive behavior in the Alaskan fur seal, Callorhinus ursinus. J. Mammal. 34:417-436.

Bertram, G. L. C. 1940. The biology of the Weddell and crabeater seals. British Graham Land Expedition Sci. Rep. 1934-37, 1:1-139.

Brown, J. L. 1964. The evolution of diversity in avian territorial systems. Wilson Bull. $6: 160-169$.

1969. Territorial behavior and population regulation in birds, a review and reevaluation. Wilson Bull. 81(3): 293-329.

Carpenter, C. R. 1962. Field studies of a primate population, p. 286-294. In E. L. Bliss [ed.], Roots of behavior. Harper, New York.

Cohen, J. E. 1969. Natural primate troops and a stocastic population model. Amer. Natur. $103: 455-477$.

Crook, J. H. 1964. The evolution of social organization and visual communication in the weaver birds (Ploceinae). Behaviour, Suppl. 10:1-178.

1965. The adaptive significance of avian social organizations. Zool. Soc. Lond. Symp. 14:181-218.

Davis, D. E. 1964. Evaluation of characters for determining age of woodehucks. J. Wildlife Manage. 28:9-15.

Downhower, J. F. 1968. Factors affecting the dispersal of yearling yellow-bellied marmots. Ph.D. Thesis. Univ. Kansas. 161 p.

Eisenberg, J. F. 1966. The social organizations of mammals, pp. 1-92. In Handbuch der Zoologie 8(39). Walter de Gruyter, Berlin.

Fisler, G. F. 1969. Mammalian organizational systems. Los Angeles County Mus. Contrib. Sci. No. 167.32 p.

Hall, E. R., and K. R. Kelson. 1959. The mammals of North America. 2 vols. Ronald, New York, 1,083 p.

Hayward, C. L. 1952. Alpine biotic communities of the Uinta Mountains, Utah. Ecol. Monogr. 22:93-120.

Hewer, H. R. 1960. Behaviour of the grey seal (Halichoerus grypus Fab.) in the breeding season. Mammalia (Paris) $24: 400-421$. 
La.ek, D. 1966. Population studies of birds. Clarendon, Oxford. 341 p.

1968. Ecological adaptations for breeding in birds. Methuen, London. $409 \mathrm{p}$.

Lack, D., and J. T. Emlen, Jr. 1939. Observations on breeding biology in tricolored redwings. Condor $41: 225-230$.

McLaren, I. A. 1967. Seals and group selection. Ecology 48:104-110.

Michael, R. P. 1969. Effects of gonadal hormones on displaced and direct aggression in pair's of rhesus monkeys of opposite sex, pp. 172-178. In S. Garattini and E. B. Sigg [ed.], Aggressive behavior: proceedings of the international symposium on biology of aggressive behavior. Wiley, New York.

Nee, J. A. 1969. Reproduction in a population of yellow-bellied marmots (Marmota flaviventris). J. Mammal. 50(4):756-765.

Nero, R. W. 1963. Comparative behavior of the yellow-headed blackbird, redwing blackbird and other Ieterids. Wilson Bull. 75:376-413.

Nero, R. W., and J. T. Emlen, Jr. 1951. An experimental study of territorial behavior in breeding red-winged blackbirds. Condor $53(3): 105-116$.

Orians, G. H. 1961. The ecology of blackbird (Agelains) social systems. Ecol. Monogr. $31: 185-312$.

1969. On the evolution of mating systems in birds and mammals. Amer. Natur. $103: 589-603$.

Orians, G. H., and G. M. Christman. 1968. A comparative study of red-winged, tricolored and yellow-headed blackbirds. Univ. Calif. Pub. Zool. 84.85 p.

Pattie, D. L. 1967. Observations on an alpine population of yellow-bellied marmots (Marmota flaviventris). Northwest Sci. 41:96-102.

Rand, R. W. 1955. Reproduction in the female cape fur seal, Arctocephalus pusillus (Sehreber). Zool. Soc. London, Proc. 124:717-740.

Shirer, H. W., and J. F. Downhower. 1969. Radio tracking of dispersing yellow-bellied marmots. Kansas Acad. Sci., Trans. 71(4):463-479.

U.S. Weather Bureau. 1962-1968. Climatological data-Colorado. Vols. 67-73. U.S. Government Printing Office, Washington, D.C.

Verner, J. 1964. Evolution of polygamy in the long-billed marsh wren. Evolution 18:252261.

Verner, J., and M. F. Willson. 1966. The influence of habitats on mating systems of North American passerine birds. Ecology $47: 143-147$.

- 1969. Mating systems, sexual dimorphism, and the role of male North American passerine birds in the nesting cycle. Amer. Ornithologists' Union. Ornithological Monogr. No. $9.76 \mathrm{p}$.

Wynne-Edwards, V. C. 1962. Animal dispersion in relation to social behavior. Oliver \& Boyd, Edinburgh. 653 p. 